Received Date :

18-Aug-2011

Revision Requested:

20-Sep-2011

Revised Date :

19-Dec-2011

Accepted Date :

04-Jan-2012

Article type :

Review Article

Review

\title{
MELATONIN AND THE METABOLIC SYNDROME: A TOOL FOR EFFECTIVE THERAPY IN OBESITY-ASSOCIATED ABNORMALITIES?
}

Frederic Nduhirabandi ${ }^{1}$, Eugene $\mathrm{F}$ du Toit ${ }^{2}$, Amanda Lochner ${ }^{1 *}$

${ }^{1}$ Division of Medical Physiology, Department of Biomedical Sciences, Faculty of Health

Sciences, Stellenbosch University, South Africa; ${ }^{2}$ School of Medical Science, Griffith

University, Australia

* Corresponding address: Prof Amanda Lochner

Department of Biomedical Sciences,

Faculty of Health Sciences,

PO Box 19063

Tygerberg

7505

Republic of South Africa

Tel: $\quad 27219389391$

Fax: $\quad 27219389476$

E-mail: alo@sun.ac.za

Key words: Cardiovascular effects, insulin resistance, leptin resistance, melatonin, metabolic syndrome, obesity 


\section{Abstract:}

The metabolic syndrome is a cluster of metabolic abnormalities associated with increased risk for cardiovascular diseases. Apart from its powerful antioxidant properties, the pineal gland hormone melatonin has recently attracted the interest of various investigators as a multifunctional molecule. Melatonin has been shown to have beneficial effects in cardiovascular disorders including ischaemic heart disease and hypertension. However its role in cardiovascular risk factors including obesity and other related metabolic abnormalities is not yet established, particularly in humans. New emerging data show that melatonin may play an important role in body weight regulation and energy metabolism. This review will address the role of melatonin in the metabolic syndrome focusing on its effects in obesity, insulin resistance and leptin resistance. The overall findings suggest that melatonin should be exploited as a therapeutic tool to prevent or reverse the harmful effects of obesity and its related metabolic disorders.

\section{Introduction}

The metabolic syndrome (MetS), also termed syndrome $\mathrm{X}$ or insulin resistance syndrome, represents a cluster of metabolic abnormalities including, amongst others, abdominal obesity, insulin resistance, glucose intolerance, atherogenic dyslipidaemia, raised blood pressure and a pro-inflammatory state (Cornier et al.2008). In addition to an increased risk for cardiovascular diseases and type 2 diabetes, this syndrome is also associated with numerous co-morbidities such as non-alcoholic fatty liver disease, reproductive disorders, obstructive sleep apnoea syndrome, osteoarthritis and some cancers (Pothiwala et al. 2009). MetS patients exhibit also sleep/wake disturbances and other circadian abnormalities (Cardinali et al. 2011, Reiter et al. 2011). 
Available evidence indicates that in most developed and developing countries between $20 \%$ and $30 \%$ of the adult population can be characterized as having MetS (Grundy 2008) with obesity (increased body fat accumulation due to excessive nutrient/energy intake) playing an important role in the development of this condition (Cornier et al. 2008). Previous strategies to combat the prevalence of obesity and the MetS have not yet been successful and it is predicted that up to $58 \%$ of the global adult population could be either overweight or obese by 2030 (Kelly et al. 2008). This alarming prevalence and an increased risk for numerous co-morbidities will have serious socio-economic implications for both government and society in the future (Haslam \& James 2005).

The pathophysiological mechanisms involved in the development of obesity-induced MetS, from adipose tissue dysregulation to a chronic inflammatory state, are complex and not well understood. In this regard, several mechanisms in connection with increased body fat accumulation and insulin resistance have been proposed including, amongst others, generation of lipid metabolites, inflammation, and cellular stress (oxidative and endoplasmic reticulum stress) (for review see Boden (2011)). Support for a potential role of oxidative stress in the MetS is rapidly increasing (Roberts \& Sindhu 2009, Hopps et al .2010, Otani 2011). A recent USA national survey showed that MetS patients were found to have a low serum antioxidant capacity compared with those without MetS (Beydoun et al. 2011). Therefore, along with other substantial interventions (e.g., sustained lifestyle modification with calorie restriction, increased physical activity and adjuvant drugs), antioxidant supplementation in the management of the MetS or prevention of increased oxidative stress associated with obesity-related alterations are currently receiving much attention.

The pineal gland hormone melatonin has potent antioxidant activities (Korkmaz et al. 2009a). In addition, it has been shown to play a role in metabolic regulation (Korkmaz et al. 2009b, Tan et al. 2011). Convincing evidence exists for the association of circadian system derangement (chronodisruption), sleep deprivation, and melatonin suppression in MetS and obesity (Reiter et 
al. 2011). The present review discusses the effects of melatonin in obesity-associated metabolic alterations focusing on body weight/adiposity and resistance to the actions of insulin and leptin, two important hormones involved in metabolic regulation (Benoit et al. 2004). The role of melatonin as a multifunctional molecule and its potential cardiovascular effects are also summarized. Particular attention must be paid to the fact that the overall role of melatonin in obesity-related disorders is due more likely to its combined pleiotropic regulatory effects rather than to its antioxidant activities alone (Hardeland et al. 2011). In this regard, the obesityassociated oxidative stress and eventual antioxidant interventions in obesity and insulin resistant states will not be discussed since they have been largely reviewed elsewhere (Houstis et al. 2006, Vincent et al. 2007, Grattagliano et al. 2008, Hopps et al. 2010, Otani 2011, Rains \& Jain 2011).

\section{Melatonin: a multifunctional molecule more than an antioxidant}

Melatonin or $\mathrm{N}$-acetyl-5-methoxytryptamine is the hormone secreted mainly by the pineal gland which is under the control of the central nervous system via the suprachiasmatic nucleus (SCN) of the hypothalamus. Since the pineal gland is active only in darkness, the levels of melatonin in the pineal gland and in blood are high at night and low during the day (Altun et al. 2002). The biosynthesis and metabolism of melatonin has recently been extensively reviewed (PandiPerumal et al. 2006, Hardeland 2008).

Viewed as nature's most versatile biological signaling (Pandi-Perumal et al. 2006) and multitasking molecule (Reiter et al. 2010), melatonin is a highly conserved molecule found in almost all groups of organisms (Hardeland \& Fuhrberg 1996). Beside its classical role as a chronobiotic factor or endogenous synchronizer participating in regulation of seasonal as well as circadian rhythm (Zawilska et al. 2009), melatonin is also involved in a wide range of physiological functions in humans and animals having anti-excitatory, antioxidant, antiinflammatory, immunomodulatory and vasomotor effects (for review see Hardeland et al.(2006), Pandi-Perumal et al.(2006)). Many of the biological actions of melatonin are elicited through 
activation of membrane (Hardeland et al.2006, Pandi-Perumal et al.2008) or nuclear (Wiesenberg et al. 1998, Carlberg 2000) receptors while some of its intracellular actions are receptor-independent (for example, free radical scavenging). Two types of membrane receptors have been identified in mammals: melatonin receptor type1 (MT1 in rodents or MTNR1A in humans) and type 2 (MT2 in rodents or MTNR1B in humans); they belong to the family of Gprotein-coupled receptors (for review see Hardeland et al. (2011)) and are increased in type 2 diabetic patients (Peschke et al. 2007).

The antioxidant activity of melatonin is well established (for reviews see Tan et al. (2007), Korkmaz et al. (2009a)). Most of studies used melatonin at very high concentrations $(1 \mu \mathrm{M}$ to $100 \mathrm{mM}$ ) compared to its physiological concentrations (10-60 pM and 43-400pM during the day and the night, respectively) (Barrenetxe et al. 2004, Bonnefont-Rousselot \& Collin 2010). In both in vitro and in vivo experiments, melatonin administration was able to neutralize a number of toxic reactants including reactive oxygen species (ROS) and free radicals (Reiter et al. 2000, Reiter et al. 2008) and no toxicity was found when melatonin was administered to experimental animals or humans at doses varying between $1 \mathrm{mg}$ and 300mg per day (Bonnefont-Rousselot \& Collin 2010)). It has also been shown to increase the expression and activity of glutathione peroxidase (GPx), superoxide dismutase (SOD) and catalase (Vural et al. 2001, Rodriguez et al. 2004) and to increase the efficacy of classic antioxidants such as vitamin E, vitamin C and glutathione (GSH) (Gitto et al. 2001). Furthermore, several melatonin metabolites (e.g., N1acetyl-N2-formyl-5-methoxykynuramine (AFMK)) which are formed when melatonin neutralizes damaging reactants are themselves free radical scavengers (Tan et al. 2007, Reiter et al. 2008). This would increase the efficacy of melatonin in pathological conditions associated with increased oxidative stress (Korkmaz et al. 2009a, Bonnefont-Rousselot \& Collin 2010). Importantly, melatonin treatment protects against mitochondrial dysfunction, the major source of reactive oxygen and nitrogen species (ROS/RNS) (Lopez et al. 2009, Paradies et al. 2010). 
Melatonin is a small, highly lipophilic and hydrophilic molecule able to cross all morphological barriers and acts not only in every cell but also within every subcellular compartment (Vural et al. 2001, Rodriguez et al. 2004). These pleiotropic activities have led to the suggestion that it may be used clinically in disease conditions where its circulating levels are reduced such as in cardiovascular diseases (Reiter et al. 2010a) and diabetes (Peschke 2008) as well as in cancer (Srinivasan et al. 2008). The description of the role of melatonin in these conditions is beyond the focus of this review and only the cardiovascular effects of melatonin will be summarized.

\section{Cardiovascular effects of melatonin}

Endogenous melatonin has been shown to play an important role in the cardiovascular system (CVS) (Dominguez-Rodriguez et al. 2010, Reiter et al. 2010a). As indicated above, melatonin exerts its physiological functions through its chronobiotic, anti-excitatory, antioxidant, antiinflammatory, immunomodulatory and vasomotor activities (Pandi-Perumal et al. 2006). Indeed, the CVS is connected to the SCN via multisynaptic autonomic neurons, and evidence confirmed that melatonin affects the CVS via these activities (Ruger \& Scheer 2009, Dominguez-Rodriguez et al. 2010). Moreover, melatonin receptors (MT1/MT2) have been identified in the heart and arteries (Ekmekcioglu et al. 2003). Melatonin has been reported to influence blood pressure (Kitajima et al. 2001) and heart function (Abete et al. 1997) directly and/or indirectly by affecting cardiovascular risk factors including, amongst others, increased visceral fat accumulation and dyslipidaemia (Agil et al. 2011a, Kozirog et al. 2011, Nduhirabandi et al. 2011). The latter will be discussed in the section on obesity and insulin resistance (see figure 1 and table1). Importantly, subjects with coronary heart disease had impaired nocturnal melatonin secretion (Brugger et al. 1995, Altun et al. 2002) while those with myocardial infarction (Dominguez-Rodriguez et al. 2002) and hypertension (Forman et al. 2010) were found to have low circulating melatonin levels. Interestingly, a recent case-control study done by Samimi-Fard et al. (2011) showed a significant association between single nucleotide 
polymorphisms (SNPs) (rs28383653) of melatonin receptor type 1A (MT1A) and coronary artery disease.

Melatonin has potent cardioprotective properties against ischaemia/reperfusion injury (Tengattini et al. 2008, Dominguez-Rodriguez et al. 2009). The study done by Sahna et al. (2002a) reported a bigger post-ischaemic myocardial infarction in pinealectomized rats compared to non-pinealectomized rats, indicating for the first time the cardioprotective effects of endogenous melatonin. The same study and additional investigations in our laboratory (Lochner et al. 2006, Genade et al. 2008) and elsewhere ( Sahna et al. 2002b, Sahna et al. 2005, Petrosillo et al. 2009, Lamont et al. 2011) have confirmed that the short- or long-term administration of melatonin at either physiological or pharmacological doses protected the heart against myocardial ischaemia/reperfusion damage. Futhermore, the beneficial effects of exogenous melatonin on the heart in physiological conditions such as ageing (Petrosillo et al. 2010) as well as in pathophysiological conditions, for example hyperthyroidism (Ghosh et al. 2007), cadmium-induced oxidative damage (Mukherjee et al. 2011) and myocardial hypertrophy (Reiter et al. 2010b) have been demonstrated. However, the mechanism of the actions of melatonin is still complex and not yet fully explored. Besides its direct free radical scavenger and indirect antioxidant activity (Tengattini et al. 2008), the contribution of MT receptors in the cardioprotective properties has also been emphasized (Arvola et al. 2006, Sallinen et al. 2007, Genade et al. 2008, Grossini et al. 2011, Lamont et al. 2011).

Melatonin supplementation has largely been considered as a potential pharmacological agent in non-dipper and individuals with hypertension (Paulis \& Simko 2007, Reiter et al. 2009, Grossman et al. 2011, Kozirog et al. 2011). Melatonin was reported to reduce systolic blood pressure along with aortic pulse wave velocity which is regarded as an important indicator of total cardiovascular risk estimation (Yildiz \& Akdemir 2009). A recent meta-analysis of randomized controlled trials by Grossman et al. (2011) indicated that melatonin administration (at 2mg: controlled-release preparation) was effective to reduce nocturnal systolic and diastolic 
blood pressure in patients with nocturnal hypertension. The regulation and modulation of blood pressure is a complex mechanism with multifactorial aspects (Paulis \& Simko 2007). Several reports have indicated a direct effect of melatonin on blood pressure through its anti-adrenergic effects and nitric oxide availability (Kitajima et al. 2001, Paulis \& Simko 2007). It appears however, as pointed out by Paulis \& Simko (2007), that controversial in vitro results complicate the explanation of the overall effect on blood pressure in vivo while different vascular responses depending on the type of vascular bed (Cook et al. 2011) have also been reported. For example melatonin administration caused vasoconstriction in isolated coronary arteries (Tunstall et al. 2011) and the renal vascular bed (Cook et al. 2011) as opposed to vasodilatation in the aorta, pulmonary and umbilical vascular bed (Thakor et al. 2010). In contrast to the vasoconstriction observed in porcine isolated coronary arteries (Tunstall et al. 2011), intracoronary infusion of melatonin $\left(70 \mathrm{pgmL}^{-1}\right.$ per minute of coronary blood flow) in anaesthetized pigs, was followed by an increased coronary flow and cardiac function through the beta-adrenoreceptors and nitric oxide (Grossini et al. 2011). These inconsistent vasomotor effects could be due to difference in the expression of the type of MT1/MT2 receptor in some vascular regions and involvement of the autonomic nervous system (Grossini et al. 2011).

Although more clinical investigations are required, melatonin appears to be an effective cardioprotectant in non-obese animals in addition to its promising antihypertensive effects. Since obesity is strongly associated with the increased prevalence of cardiovascular disorders (Poirier et al. 2006) which have been linked to derangement of melatonin's circadian rhythm (Altun et al. 2002, Reiter et al. 2009, Dominguez-Rodriguez \& Abreu-Gonzalez 2011), the role of melatonin in obesity/overweight and other related MetS components (insulin resistance, glucose intolerance, atherogenic dyslipidaemia, elevated blood pressure) is the topic of many investigations. 


\section{Melatonin and obesity}

Melatonin is involved in energy expenditure and body fat mass regulation (Korkmaz et al. 2009b, Tan et al. 2011). Previously reported in seasonal animals (Bartness \& Wade 1985), the role of melatonin in body weight regulation was clearly demonstrated by the observation that the reduction in circulating melatonin in pinealectomized rats was followed by an increase in body weight and that intraperitoneal (ip) administration of melatonin $\left(30 \mathrm{mgkg}^{-1}\right.$ per day for 3 weeks) to these pinealectomized animals reversed the body weight gain (Prunet-Marcassus et al. 2003). In non-pathological conditions, melatonin has been shown to directly mediate body weight reduction and loss of adipose tissue: daily oral melatonin supplementation $\left(0.4 \mu \mathrm{gml}^{-1}\right.$ to $4 \mu \mathrm{gml}^{-1}$ for 12 weeks) in middle-aged rats increased plasma melatonin and reduced body weight, visceral adiposity, and plasma insulin and leptin levels to youthful levels (Rasmussen et al. 1999, Wolden-Hanson et al. 2000). Similar effects on body weight and visceral fat were observed in young rats (Bojkova et al. 2006, Kassayova et al. 2006). Interestingly, these weight loss effects of melatonin are independent of energy intake (for a review see Tan et al. (2011)).

The effects of melatonin in obesity have been intensively studied in animal models of dietinduced obesity (Nishida et al. 2002, Prunet-Marcassus et al. 2003, Puchalski et al. 2003, Hussein et al. 2007, Sartori et al. 2009, She et al. 2009, Shieh et al. 2009, Rios-Lugo et al. 2010, Agil et al. 2011a, Cardinali et al. 2011, Nduhirabandi et al. 2011). It was shown that the amplitude of the nocturnal pineal (Cano et al. 2008) and serum (Peschke et al. 2006) melatonin peaks decrease significantly in obese animals. Daily melatonin supplementation $\left(4-10 \mathrm{mg} \mathrm{kg}^{-1}\right.$ for 8 to 12 weeks) significantly reduced body weight as well as plasma glucose, leptin, triglyceride (TG) and total cholesterol levels of the rat models of high-fat diet-induced obesity (Prunet-Marcassus et al. 2003, She et al. 2009, Rios-Lugo et al. 2010). Using a rat model of high-calorie diet-induced obesity, our laboratory has demonstrated that long-term oral melatonin consumption ( $4 \mathrm{mg} \mathrm{kg}^{-1}$ per day for 16 weeks) starting before the establishment of obesity attenuated weight gain and prevented the development of obesity-induced metabolic 
alterations (elevated visceral fat, serum insulin, leptin, TG and reduced high density lipoprotein cholesterol (HDL-C)) (Nduhirabandi et al. 2011). This study also reported for the first time the protective effects of melatonin against the increased susceptibility to myocardial ischaemia and reperfusion damage of the hearts from obese rats. We found that melatonin administration reduced post- ischaemic myocardial infarct size and improved myocardial function recovery via activation of reperfusion injury salvage protein kinases (PKB/Atk and ERK1/2) (Nduhirabandi et al. 2011). However, how melatonin affects the heart in obesity needs further investigation to determine the underlying mechanisms and the role of its direct or indirect actions.

Beside these metabolic effects, the antioxidant activities of melatonin were also demonstrated in animal models of diet-induced obesity: daily melatonin administration to obese rabbits $\left(1 \mathrm{mgkg}^{-1}\right.$ subcutaneously for 4 weeks)(Hussein et al. 2007$)$ or rats $\left(4 \mathrm{mgkg}^{-1}\right.$, ip for 8 weeks) (She et al. 2009) improved the metabolic profile (reduction in body weight gain, blood glucose, triglycerides, cholesterol, low density lipoprotein cholesterol (LDL-C)) and increased the levels of glutathione peroxidase (GSH-Px) and HDL-C. Additionally, melatonin administration reduced oxidative stress as indicated by plasma malondialdehyde (MDA) levels and increased superoxide dismutase (SOD) activity to control levels (She et al. 2009). These changes were also associated with amelioration of blood pressure, heart rate, sympathetic activities and other obesity-related morphological pathologies including disappearance of fatty changes in the liver and kidney as well as atheromatous changes in the blood vessels (Hussein et al. 2007).

Despite the studies on the antioxidant activities of melatonin in experimental obese animals, only few have been done in obese humans. In a recent promising study done by Kozirog et al. (2011), one month of administration of melatonin (5mg per day) to patients with MetS reduced the body mass index (BMI), systolic blood pressure (SBP) and plasma fibrinogen as well as thiobarbituric acid reactive substrates (TBARS) levels. Interestingly, after two months of treatment, there was a further significant improvement of SBP and antioxidative status as indicated by an elevated catalase activity and a decrease in low density lipoprotein cholesterol 
(LDL-C) levels (Kozirog et al. 2011). Although no information was given about the levels of circulating melatonin and insulin, this report pointed out, as claimed by other authors, that the levels of melatonin per se are not as important as the melatonin/insulin ratio which correlates negatively with the lipid profile of patients with MetS (Robeva et al. 2008).

The impact of obesity on the overall circulating melatonin levels in humans has been marked by divergences. For example, while the mean nocturnal serum melatonin was reported to be lower in patients with type 2 diabetes (Peschke et al. 2006) and coronary heart disease (see Cardinali et al. (2011)) and higher in severe obesity (Shafii et al. 1997), the study done by Rojdmark et al. (Rojdmark et al. 1991) showed that there were no significant modifications of melatonin secretion and excretion in obesity. Additional studies indicated that circulating melatonin levels in pre-diabetic obese male (Robeva et al. 2006) and male and female obese diabetic (Robeva et al. 2008) patients with MetS did not differ from controls. These discrepancies may be due to various factors including age of patients and severity of obesity (Shafii et al. 1997).

MT receptor-mediated pathways may play an important role in melatonin's actions in obesity. This was evidenced by studies using the melatonin agonist NEU-P11 (10 $\mathrm{mg} \mathrm{kg}^{-1}$ per day for 8 weeks, ip) (She et al. 2009) or Ramelteon, a potent selective MT1/MT2 receptor agonist (8 mg $\mathrm{kg}^{-1}$ per day for 8 weeks, oral) (Oxenkrug \& Summergrad 2010): it was found that melatonin agonist administration exerts similar regulatory effects as melatonin, namely decreasing body weight and blood pressure. Using MT receptor knock out mice, Muhlbauer et al. (2009) demonstrated an active role for these receptors in the synchronisation of the major organs involved in blood glucose regulation and that they act negatively on insulin secretion. Since MT receptors are also present in adipose tissue (Brydon et al. 2001), it seems that the overall effects of melatonin in obesity are partly mediated through these receptors in addition to activation of the sympathetic nervous system via hypothalamic receptors and subsequent effects on lipolysis and adipose tissue plasticity (Penicaud et al. 2000, Song \& Bartness 2001, Bartness et al. 2002). 
In vitro melatonin treatment of adipocytes has been shown to possibly inhibit differentiation and limit adipose tissue hypertrophy (Alonso-Vale et al. 2009) by inhibiting fatty acid-induced triglyceride accumulation in cells exposed to physiological levels of oleic acid (Sanchez-Hidalgo et al. 2007). This could explain how in vivo melatonin treatment prevents the increase in circulating triglycerides and eventually body fat accumulation and body weight gain in overweight and obesity (Agil et al. 2011a, Nduhirabandi et al. 2011). The reduction in body weight gain might be due to a significant decrease in fat content as opposed to lean body mass (Wolden-Hanson et al. 2000) and could be related to improvements in the compromised insulin and leptin signaling associated with obesity (Sartori et al. 2009) (see details in the following sections).

The exact mode of action of melatonin in body weight regulation is however complex and not fully elucidated. The exact mode of action of melatonin in body weight regulation is however complex and not fully elucidated. As previously indicated the divergences in melatonin activities may be explained by differences in experimental protocols. For instance, while body weight reduction following melatonin administration was independent of food intake in middle-aged male rats (Wolden-Hanson et al. 2000) and obese rats (She et al. 2009, Agil et al. 2011a), it was accompanied with a decrease in food consumption in ovariectomized rats (SanchezMateos et al. 2007) and obese rabbits (Hussein et al. 2007). It appears that melatonin's effects could vary from one study to another depending on the study design: the dose, mode and time of administration as well as the age, sex, species and strain of the animal model. For example, following a prolonged oral melatonin administration to normal rats, serum glucose levels were increased in male and female 48-hours fasted animals (Bojkova et al. 2006), decreased in overnight fasted females (Bojkova et al. 2006) or in both males and females (Kassayova et al. 2006) or unchanged in either sexes of non-fasted animals (Markova et al. 2003). Whether the overall effect of melatonin administration in obesity results from its direct or/and indirect actions requires further research. 


\section{Melatonin and insulin resistance}

Insulin resistance is characterized by a decreased cellular sensitivity to its effects on glucose uptake, metabolism and storage in peripheral tissues (for more details see Benito (2011), Tesauro \& Cardillo (2011)). Although not all overweight/ obese persons develop insulin resistance and a normal weight does not equate to insulin sensitivity (McLaughlin et al. 2004), obesity is the most important factor in the etiology of insulin resistance (Cornier et al. 2008). It is generally accepted that hyperinsulinaemia and insulin resistance are the common links between obesity and its vascular complications (for review see Tesauro \& Cardillo (2011)).

Melatonin has been implicated in regulation of insulin secretion and glucose/lipid metabolism (Nishida 2005, Peschke 2008, Peschke \& Muhlbauer 2010). Studies on pinealectomized animals also gave more insight into the role of melatonin in insulin resistance: in normal rats, pinealectomy induced insulin resistance and glucose intolerance (Lima et al. 1998, Zanquetta et al. 2003). In type 2 diabetic rats, pinealectomy increased plasma insulin significantly (after 21 weeks) and caused accumulation of triglycerides which was followed later (after 35 weeks) by a net decrease in insulin levels (Nishida et al. 2003), reflecting impairment in insulin release from pancreatic $\beta$-cells, as seen in patients at an advanced stage of type 2 diabetic mellitus (Kuzuya et al. 2002).

Pineal gland melatonin synthesis is decreased in type 2 diabetic Goto-Kakizaki rats (Frese et al. 2009); long term melatonin consumption $\left(2.5 \mathrm{mgkg}^{-1}\right.$ per day for 9 weeks) increased plasma melatonin levels with a concomitant reduction in insulin levels in these animals (Peschke et al. 2010). Sartori et al. (2009) found that 8 weeks oral melatonin (100 $\mathrm{mg} \mathrm{kg}^{-1}$ per day) markedly improved insulin sensitivity and glucose tolerance in mice on a high-fat diet. A similar finding was associated with an increase in hepatic glycogen and improvement in liver steatosis following 2 weeks of melatonin administration $\left(10 \mathrm{mgkg}^{-1}\right.$ per day, ip) in high-fat diet-induced diabetic mice (Shieh et al. 2009). In high fat/high sucrose-fed rats, 8 weeks treatment with melatonin or its agonist NEU-P11 increased insulin sensitivity (She et al. 2009). Besides the 
reduction in plasma hyperinsulinaemia, chronic melatonin administration $\left(1.1 \mathrm{mgkg}^{-1}\right.$ per day for 30 weeks, subcutaneously via implanted melatonin-releasing pellets) to rats with type 2 diabetes mellitus reduced the hyperlipidaemia, and hyperleptinaemia (Nishida et al. 2002). This long term melatonin-induced improvement of insulin sensitivity may therefore be linked to a reduced body weight and improved lipid metabolism as it was recently demonstrated in young Zucker diabetic fatty rats (Agil et al. 2011a \& b). Although 2 weeks of melatonin administration (1 or $10 \mathrm{mg} \mathrm{kg}^{-1}$ per day, ip starting at 4 weeks) did not affect the body weight of rats fed a highfructose diet for 6 weeks, it ameliorated insulin resistance (Kitagawa et al. 2011). This was associated with increase in serum adiponectin levels and reduction in leptin levels (Kitagawa et al. 2011). Interestingly, melatonin administration attenuated the levels of circulating free fatty acids (FFA) and serum tumor necrosis factor- $\alpha$ (TNF- $\alpha$ ) (Kitagawa et al. 2011), two important factors implicated in the development of insulin resistance and vascular dysfunction in obesity (Benito 2011, Tesauro \& Cardillo 2011).

On a cellular level, insulin resistance is associated with abnormal or compromised intracellular insulin signaling cascade. This cascade principally includes binding of insulin to insulin receptor (IR), tyrosine phosphorylation of insulin receptor substrate (IRS) proteins and activation of phosphotidylinositol-3-kinase (PI-3K), protein kinase B (PKB/Akt) and protein kinase C (PKC) isoforms (for details see Benito (2011)). Melatonin (1nM) treatment has been shown to stimulate glucose transport in skeletal muscle via the phosphorylation and activation of IRS-I and $\mathrm{Pl}-3 \mathrm{~K}$ respectively ( $\mathrm{Ha}$ et al. 2006). It was further demonstrated that melatonin improves glucose homeostasis by restoring the vascular actions of insulin which were characterized by increased phosphorylation of Akt and endothelial nitric oxide synthase (eNOS) in aortic tissue

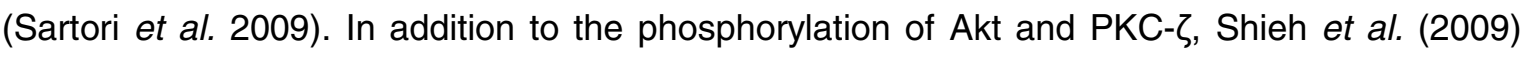
indicated that melatonin $(1 \mathrm{nM})$ stimulated glycogen synthesis and increased the phosphorylation of glycogen synthase kinase 3 B (GSK3-ß) in hepatic cells. More interestingly, the effects of melatonin could be blocked by using the non-selective MT1/MT2 antagonist, luzindole, or the MT2 selective antagonist, 4-phenyl-2-propionamido tetraline (4P-PDOT) (Ha et 
al. 2006, Shieh et al. 2009), suggesting MT receptor involvement. It is not clear however how activation of the high affinity MT receptors which are G-protein linked leads to stimulation of the IRS-1/PI-3K pathway and the role of PKC- $\zeta$ in this regard (see figure 2). In addition, the role of $\mathrm{PKB} / \mathrm{Akt}$ is not clear in view of the different results that have been reported showing its activation in skeletal muscle cells (Ha et al. 2006) as opposed to its inactivation in hepatic cells (Shieh et al. 2009).

Using adipose tissue of the female fruit bat, Cynopterus sphinx (seasonal animal), Banerjee et al. (2011) have shown that melatonin treatment $\left(100 \mathrm{ngml}^{-1}\right.$ and $\left.500 \mathrm{pgml}^{-1}\right)$ together with insulin increased the glucose uptake compared to control cells. There was however no correlation between glucose uptake and the protein expression of glucose transporter 4 (GLUT-4) in these cells (Banerjee et al. 2011). In this regard, additional exploration of GLUT4-translocation could give more insight in the results obtained. Although a decrease in GLUT-4 gene expression was reported following melatonin treatment ( $1 \mu \mathrm{M}$ for 14 days) in human brown adipocyte cells lines (PAZ6) (Brydon et al. 2001), Zanquetta et al. (2003) found that 30 days of calorie restriction or melatonin replacement $\left(50 \mu \mathrm{g} 100 \mathrm{~g}^{-1}\right.$ per day i.p.) to pinealectomised rats was accompanied by increased plasma membrane GLUT-4 protein content in white adipose tissue to values similar to those of control rats. Importantly, Gosh and coworkers (2007) found that melatonin protected against oxidative damage and restored expression of GLUT-4 gene in the hyperthyroid rat heart, establishing the ability of antioxidants to reverse oxidative stressmediated metabolic derangements. We have recently observed that acute melatonin (100nM) treatment enhances the insulin action on glucose uptake of normal isolated adult cardiomyocytes (Nduhirabandi et al. unpublished data). However, further experiments are needed to fully explore the role of melatonin in glucose homeostasis.

Further support for a role of melatonin in the regulation of energy metabolism came from the recent finding that removal of the melatonin receptor type I (MT1) significantly impairs the ability of mice to metabolize glucose and probably induces insulin resistance in these animals 
(Contreras-Alcantara et al. 2010). Epidemiological studies have also revealed that variants near/in the melatonin receptor type 1B (MTNR1B) are associated with elevated plasma fasting glucose levels (Kan et al. 2010) and impaired insulin secretion (Tam et al. 2010).

In addition to the above, melatonin receptors MT1 and MT2 are also expressed in pancreatic islets (Peschke et al. 2000) and as insulin levels exhibit a nocturnal drop, its production has been suggested to be controlled, at least in part, by melatonin (Mulder et al. 2009). Indeed, melatonin administration inhibits insulin secretion in rat pancreatic islets (Picinato et al. 2002, Peschke 2008) and could explain why melatonin reduced the fasting insulin levels (Puchalski et al. 2003, She et al. 2009). Importantly, a recent case study done by (Nieuwenhuis et al. 2009) demonstrated a potentially important role of melatonin in diabetes by successfully treating a $40-$ year-old woman with insulin-dependent diabetes mellitus (IDDM) with phototherapy. Indeed, the exposure to the light during phototherapy could suppress melatonin production as expected and this could lead to an increase in insulin secretion which is low in IDDM and causing a subsequent improvement in glucose metabolism.

However, in the case of type 2 diabetes, as pointed out by Peschke \& Muhlbauer (2010), the exploitation of melatonin's inhibitory effect on insulin secretion as a potential therapy to reduce hyperinsulinaemia requires prudence and more large clinical studies. The implication of catecholamines as causal factor controlling the biological relevance of melatonin-insulin interaction has recently been demonstrated in type 1 and 2 diabetes (Peschke et al. 2011). It was observed that catecholamines (noradrenaline and adrenaline) and melatonin levels were reduced in type 2 diabetic GK rats (characterized by high insulin levels) and elevated in type 1 diabetic rats (associated with reduced insulin levels) (Peschke et al. 2011). The role of cathecolamines in these pathological conditions could be explained by their observed (high or low) levels taking into consideration the fact that catecholamines decrease insulin secretion and stimulate melatonin synthesis (Peschke et al. 2011). 


\section{Melatonin and leptin resistance}

Leptin is an adipocyte hormone that has a central role in regulating food intake, body weight and energy expenditure and leptin resistance refers to the inability of elevated circulating leptin levels to reduce common obesity. As a predisposing factor for diet-induced obesity (Scarpace \& Zhang 2009), leptin resistance is associated with insulin resistance and an increased proinflammatory state (Lago et al. 2008). Pinealectomy increases circulating leptin (Baydas et al. 2001) while exogenous melatonin decreases serum leptin levels in both pinealectomized (Canpolat et al. 2001) and intact rat models of diet-induced obesity (Wolden-Hanson et al. 2000) before decreasing plasma insulin levels (Puchalski et al. 2003). These observations suggest a secondary modulatory effect of leptin on insulin in body weight reduction (Morrison et al. 2009). On the other hand, opposite results (increased leptin levels) have also been reported following melatonin administration to normal and pinealectomized rats ( $3 \mathrm{mgkg}^{-1}$ per day, ip, for 6 months) (Baltaci \& Mogulkoc 2007) and to male C57BL/6 adult mice (10 $\mathrm{ggml}^{-1}$ in drinking water, for 1 month) (Song \& Chen 2009). In this regard, surprisingly, the study done by Baltaci and Mogulkoc (2007) showed that pinealectomy decreased body weight gain and leptin levels. Furthermore, other studies have shown that melatonin had no effect on leptin levels in menopausal women (Cagnacci et al. 2002), ovariectomized rats (Sanchez-Mateos et al. 2007) and obese horse (Buff et al. 2005). However, as expected, in a rat model of high-fructose diet induced MetS (Kitagawa et al. 2011) and in young Zucker diabetic fatty rats (Agil et al. 2011b) melatonin administration reduced serum leptin levels. Apart from differences in experimental designs and animal models, the causes of these controversial results remain to be clarified.

At a molecular level, the mechanisms of leptin resistance and impaired leptin signaling includes amongst other things increased activity of suppressor of cytokine signaling 3 (SOCS3) (Bjorbaek et al. 1999, Emilsson et al. 1999) which is a member of a family of proteins which inhibits the JAK-STAT signaling cascade (Myers et al. 2008). Melatonin may act initially on hypothalamic leptin and insulin receptor sensitivity (as these hormones do under normal 
conditions) and may consequently relay information about peripheral fat stores to central effectors in the hypothalamus to modify food intake and energy expenditure (Song \& Bartness 2001). In this regard, melatonin, leptin and insulin have been found to activate the same intracellular signaling pathways namely PI3K and STAT-3(Carvalheira et al. 2001, Anhe et al. 2004, Picinato et al. 2008). As a consequence, melatonin may attenuate or reverse the insulin resistance in obesity by mimicking the actions of insulin and leptin signaling via cross-talk between these pathways. Concerning the effects of leptin administration on melatonin, it was shown that leptin administration $\left(50 \mathrm{ngml}^{-1}\right)$ suppressed melatonin secretion (by pineal explants) during long days and stimulated its secretion during short days in seasonal breeding animals (Zieba et al. 2011). While further evidence is required in diet-induced obesity, it appears that an intricate relationship exists between leptin, melatonin and insulin, synchronized in circadian fashion and having profound effects on metabolism.

\section{Conclusion}

Although its experimental relevance is still to be validated in the clinical setting, several studies have demonstrated the potential beneficial actions of melatonin in the metabolic syndrome and obesity (see table 1 and figure 1). Apart from its antioxidant actions, the overall metabolic actions of melatonin are the result of its pleiotropic activities associated with multiple signaling in areas of the central nervous system and in peripheral organs (Hardeland et al. 2011). In view of the beneficial actions of melatonin on obesity-related metabolic disorders (increased body fat accumulation, glucose intolerance, atherogenic dyslipidaemia, and raised blood pressure), it would seem that melatonin treatment should indeed be exploited in the future as a tool for effective management of obesity-induced complications, including cardiovascular disease. Melatonin is an affordable, cheap and nontoxic molecule with exceptional potential to have a profound effect on public health (Reiter \& Korkmaz 2008, Sanchez-Barcelo et al. 2010). 


\section{Future perspectives}

The research on the role of melatonin and its effects on the pathophysiological mechanisms of obesity and metabolic syndrome is a recent, large and growing field. From a circadian system derangement to metabolic disorders, it involves various aspects including epidemiological, physiological and genetic factors. It is clear however, that extensive clinical trials are required to establish the clinical potential of melatonin treatment in a number of pathologies. It appears that the big challenge is the enormous variation of dosage of melatonin administered in experimental animals where low and high doses both seem to be effective. In this regard, the extrapolation of experimental findings to humans will be one of the first obstacles, but this is facilitated by the no-toxicity of melatonin even at high dosage.

\section{Acknowledgements:}

We would like to thank Prof Barbara Huisamen for her valuable comments on the manuscript.

Conflict of interest: There is no conflict of interest. 


\section{REFERENCES}

Abete, P., Bianco, S., Calabrese, C., Napoli, C., Cacciatore, F., Ferrara, N. \& Rengo, F. 1997. Effects of melatonin in isolated rat papillary muscle. FEBS Lett 412, 79-85.

Agil, A., Navarro-Alarcon, M., Ruiz, R., Abuhamadah, S., El-Mir, M.Y. \& Vazquez, G.F. 2011a. Beneficial effects of melatonin on obesity and lipid profile in young Zucker diabetic fatty rats. $J$ Pineal Res 50, 207-212. doi: 10.1111/j.1600-079X.2010.00830.x; 10.1111/j.1600079X.2010.00830.x.

Agil, A., Rosado, I., Ruiz, R., Figueroa, A., Zen, N. \& Fernández-Vázquez, G. 2011b. Melatonin improves glucose homeostasis in young Zucker diabetic fatty rats. J Pineal Res Epub. doi: 10.1111/j.1600-079X.2011.00928.x.

Alonso-Vale, M.I., Peres, S.B., Vernochet, C., Farmer, S.R. \& Lima, F.B. 2009. Adipocyte differentiation is inhibited by melatonin through the regulation of C/EBPbeta transcriptional activity. J Pineal Res 47, 221-227. doi: 10.1111/j.1600-079X.2009.00705.x.

Altun, A., Yaprak, M., Aktoz, M., Vardar, A., Betul, U.A. \& Ozbay, G. 2002. Impaired nocturnal synthesis of melatonin in patients with cardiac syndrome X. Neurosci Lett 327, 143-145.

Anhe, G.F., Caperuto, L.C., Pereira-Da-Silva, M., Souza, L.C., Hirata, A.E., Velloso, L.A., Cipolla-Neto, J. \& Carvalho, C.R. 2004. In vivo activation of insulin receptor tyrosine kinase by melatonin in the rat hypothalamus. $J$ Neurochem $90,559-566$. doi: $10.1111 / \mathrm{j} .1471-$ 4159.2004.02514.x.

Arvola, L., Bertelsen, E., Lochner, A. \& Ytrehus, K. 2006. Sustained anti-beta-adrenergic effect of melatonin in guinea pig heart papillary muscle. Scand Cardiovasc J 40, 37-42. doi: 10.1080/14017430500339347.

Baltaci, A.K. \& Mogulkoc, R. 2007. Pinealectomy and melatonin administration in rats: their effects on plasma leptin levels and relationship with zinc. Acta Biol Hung 58, 335-343. doi: 10.1556/ABiol.58.2007.4.1.

Banerjee, A., Udin, S. \& Krishna, A. 2011. Regulation of leptin synthesis in white adipose tissue of the female fruit bat, Cynopterus sphinx: role of melatonin with or without insulin. Exp Physiol 96, 216-225. doi: 10.1113/expphysiol.2010.055129.

Barrenetxe, J., Delagrange, P. \& Martinez, J.A.2004. Physiological and metabolic functions of melatonin. J Physiol Biochem 60, 61-72.

Bartness, T.J., Demas, G.E. \& Song, C.K. 2002. Seasonal changes in adiposity: the roles of the photoperiod, melatonin and other hormones, and sympathetic nervous system. Exp Biol Med (Maywood) 227, 363-376.

Bartness, T.J. \& Wade, G.N.1985. Body weight, food intake and energy regulation in exercising and melatonin-treated siberian hamsters. Physiol Behav 35, 805-808. doi: DOI:

10.1016/0031-9384(85)90415-9. 
Baydas, G., Gursu, F., Canpolat, S., Konar, V., Yasar, A., Canatan, H. \& Kelestimur, H. 2001. Effects of pinealectomy on the circadian release pattern of leptin in male rat. Neuro Endocrinol Lett 22, 449-452.

Bekyarova, G., Tancheva, S. \& Hristova, M. 2010. The effects of melatonin on burn-induced inflammatory responses and coagulation disorders in rats. Methods Find Exp Clin Pharmacol 32, 299-303. doi: 10.1358/mf.2010.32.5.1437717.

Benito, M. 2011. Tissue specificity on insulin action and resistance: past to recent mechanisms. Acta Physiologica 201, 297-312. doi: 10.1111/j.1748-1716.2010.02201.x.

Benoit, S.C., Clegg, D.J., Seeley, R.J. \& Woods, S.C. 2004. Insulin and leptin as adiposity signals. Recent Prog Horm Res 59, 267-285.

Bertuglia, S. \& Reiter, R.J. 2007. Melatonin reduces ventricular arrhythmias and preserves capillary perfusion during ischemia-reperfusion events in cardiomyopathic hamsters. J Pineal Res 42, 55-63. doi: 10.1111/j.1600-079X.2006.00383.x.

Beydoun, M.A., Shroff, M.R., Chen, X., Beydoun, H.A., Wang, Y. \& Zonderman, A.B. 2011. Serum antioxidant status is associated with metabolic syndrome among U.S. adults in recent national surveys. J Nutr 141, 903-913. doi: 10.3945/jn.110.136580.

Bjorbaek, C., El-Haschimi, K., Frantz, J.D. \& Flier, J.S. 1999. The role of SOCS-3 in leptin signaling and leptin resistance. J Biol Chem 274, 30059-30065.

Boden, G. 2011. Obesity, insulin resistance and free fatty acids. Curr Opin Endocrinol Diabetes Obes 18, 139-143. doi: 10.1097/MED.0b013e3283444b09.

Bojkova, B., Markova, M., Ahlersova, E., Ahlers I., Adamekova, E., Kubatka, P. \& Kassayova, M. 2006. Metabolic effects of prolonged melatonin administration and short-term fasting in laboratory rats. Acta Veterinaria Brno 7521-7532.

Bonnefont-Rousselot, D. \& Collin, F. 2010. Melatonin: Action as antioxidant and potential applications in human disease and aging. Toxicology 278, 55-67. doi: DOI: 10.1016/j.tox.2010.04.008.

Brugger, P., Marktl, W. \& Herold, M. 1995. Impaired nocturnal secretion of melatonin in coronary heart disease. Lancet 345, 1408.

Brydon, L., Petit, L., Delagrange, P., Strosberg, A.D. \& Jockers, R. 2001. Functional expression of MT2 (Mel1b) melatonin receptors in human PAZ6 adipocytes. Endocrinology 142, 42644271.

Buff, P.R., Morrison, C.D., Ganjam, V.K. \& Keisler, D.H. 2005. Effects of short-term feed deprivation and melatonin implants on circadian patterns of leptin in the horse. J Anim Sci 83, 1023-1032.

Cagnacci, A., Malmusi, S., Zanni, A., Arangino, S., Cagnacci, P. \& Volpe, A. 2002. Acute modifications in the levels of daytime melatonin do not influence leptin in postmenopausal women. J Pineal Res 33, 57-60. doi: 10.1034/j.1600-079X.2002.01893.x. 
Cano, P., Jimenez-Ortega, V., Larrad, A., Reyes Toso, C.F., Cardinali, D.P. \& Esquifino, A.I. 2008. Effect of a high-fat diet on 24-h pattern of circulating levels of prolactin, luteinizing hormone, testosterone, corticosterone, thyroid-stimulating hormone and glucose, and pineal melatonin content, in rats. Endocrine 33, 118-125. doi: 10.1007/s12020-008-9066-x.

Canpolat, S., Sandal, S., Yilmaz, B., Yasar, A., Kutlu, S., Baydas, G. \& Kelestimur, H. 2001. Effects of pinealectomy and exogenous melatonin on serum leptin levels in male rat. Eur $J$ Pharmacol 428, 145-148.

Cardinali, D.P., Cano, P., Jimenez-Ortega, V. \& Esquifino, A.I. 2011. Melatonin and the metabolic syndrome: physiopathologic and therapeutical implications. Neuroendocrinology 93, 133-142. doi: 10.1159/000324699.

Carlberg, C. 2000. Gene regulation by melatonin. Ann N Y Acad Sci 917, 387-396.

Carvalheira, J.B., Siloto, R.M., Ignacchitti, I., Brenelli, S.L., Carvalho, C.R., Leite, A., Velloso, L.A., Gontijo, J.A. \& Saad, M.J. 2001. Insulin modulates leptin-induced STAT3 activation in rat hypothalamus. FEBS Lett 500, 119-124.

Contreras-Alcantara, S., Baba, K. \& Tosini, G. 2010. Removal of Melatonin Receptor Type 1 Induces Insulin Resistance in the Mouse. Obesity (Silver Spring) 18, 1861-3 doi: 10.1038/oby.2010.24.

Cook, J.S., Sauder, C.L. \& Ray, C.A. 2011. Melatonin differentially affects vascular blood flow in humans. Am Jof Physiol Heart Circ Physiol 300, H670-H674. doi: 10.1152/ajpheart.00710.2010.

Cornier, M.A., Dabelea, D., Hernandez, T.L., Lindstrom, R.C., Steig, A.J., Stob, N.R., Van Pelt, R.E., Wang, H. \& Eckel, R.H. 2008. The metabolic syndrome. Endocr Rev 29, 777-822. doi: 10.1210/er.2008-0024.

Dauchy, R.T., Blask, D.E., Sauer, L.A., Davidson, L.K., Krause, J.A., Smith, L.C. \& Dauchy, E.M. 2003. Physiologic melatonin concentration, omega-3 fatty acids, and conjugated linoleic acid inhibit fatty acid transport in rodent hind limb skeletal muscle in vivo. Comp Med 53, 186-190.

Dominguez-Rodriguez, A. \& Abreu-Gonzalez, P. 2011. Circadian variations and melatonin in the acute myocardial infarction: still a forgotten extracardiac factor. Heart 97, 1895. doi: 10.1136/heartjnl-2011-300596.

Dominguez-Rodriguez, A., Abreu-Gonzalez, P., Garcia, M.J., Sanchez, J., Marrero, F., \& de Armas-Trujillo, D. 2002. Decreased nocturnal melatonin levels during acute myocardial infarction. J Pineal Res 33, 248-252.

Dominguez-Rodriguez, A., Abreu-Gonzalez, P. \& Reiter, R.J. 2009. Clinical aspects of melatonin in the acute coronary syndrome. Curr Vasc Pharmacol 7, 367-373.

Dominguez-Rodriguez, A., Abreu-Gonzalez, P., Sanchez-Sanchez, J.J., Kaski, J.C. \& Reiter, R.J. 2010. Melatonin and circadian biology in human cardiovascular disease. J Pineal Res 49, 14-22. doi: 10.1111/j.1600-079X.2010.00773.x. 
Ekmekcioglu, C., Thalhammer, T., Humpeler, S., Mehrabi, M.R., Glogar, H.D., Holzenbein, T., Markovic, O., Leibetseder, V.J., Strauss-Blasche, G. \& Marktl, W. 2003. The melatonin receptor subtype MT2 is present in the human cardiovascular system. $J$ Pineal Res 35, 4044.

Emilsson, V., Arch, J.R., de Groot, R.P., Lister, C.A. \& Cawthorne, M.A. 1999. Leptin treatment increases suppressors of cytokine signaling in central and peripheral tissues. FEBS Lett 455, 170-174.

Forman, J.P., Curhan, G.C. \& Schernhammer, E.S. 2010. Urinary melatonin and risk of incident hypertension among young women. J Hypertens 28, 446-451. doi: 10.1097/HJH.0b013e3283340c16.

Frese, T., Bach, A.G., Muhlbauer, E., Ponicke, K., Bromme, H.J., Welp, A. \& Peschke, E. 2009. Pineal melatonin synthesis is decreased in type 2 diabetic Goto-Kakizaki rats. Life Sci 85 , 526-533. doi: 10.1016/j.lfs.2009.08.004.

Genade, S., Genis, A., Ytrehus, K., Huisamen, B. \& Lochner, A. 2008. Melatonin receptormediated protection against myocardial ischaemia/reperfusion injury: role of its antiadrenergic actions. J Pineal Res 45, 449-458. doi: 10.1111/j.1600-079X.2008.00615.x.

Ghosh, G., De, K., Maity, S., Bandyopadhyay, D., Bhattacharya, S., Reiter, R.J. \& Bandyopadhyay, A. 2007. Melatonin protects against oxidative damage and restores expression of GLUT4 gene in the hyperthyroid rat heart. J Pineal Res 42, 71-82. doi: 10.1111/j.1600-079X.2006.00386.x.

Gitto, E., Tan, D.X., Reiter, R.J., Karbownik, M., Manchester, L.C., Cuzzocrea, S., Fulia, F. \& Barberi, I. 2001. Individual and synergistic antioxidative actions of melatonin: studies with vitamin $\mathrm{E}$, vitamin $\mathrm{C}$, glutathione and desferrioxamine (desferoxamine) in rat liver homogenates. J Pharm Pharmacol 53, 1393-1401.

Grattagliano, I., Palmieri, V.O., Portincasa, P., Moschetta, A. \& Palasciano, G. 2008. Oxidative stress-induced risk factors associated with the metabolic syndrome: a unifying hypothesis. $J$ Nutr Biochem 19, 491-504. doi: 10.1016/j.jnutbio.2007.06.011.

Grossini, E., Molinari, C., Uberti, F., Mary, D.A.S.G., Vacca, G. \& Caimmi, P.P. 2011. Intracoronary melatonin increases coronary blood flow and cardiac function through $\beta$ adrenoreceptors, MT1/MT2 receptors, and nitric oxide in anesthetized pigs. J Pineal Res Epub doi: 10.1111/j.1600-079X.2011.00886.x.

Grossman, E., Laudon, M. \& Zisapel, N. 2011. Effect of melatonin on nocturnal blood pressure: meta-analysis of randomized controlled trials. Vasc Health Risk Manag 7, 577-584. doi: 10.2147/VHRM.S24603.

Grundy, S.M.2008. Metabolic syndrome pandemic. Arterioscler Thromb Vasc Biol 28, 629-636. doi: 10.1161/ATVBAHA.107.151092.

Ha, E., Yim, S.V., Chung, J.H., Yoon, K.S., Kang, I., Cho, Y.H. \& Baik, H.H. 2006. Melatonin stimulates glucose transport via insulin receptor substrate-1/phosphatidylinositol 3-kinase pathway in C2C12 murine skeletal muscle cells. J Pineal Res 41, 67-72. doi: 10.1111/j.1600079X.2006.00334.x. 
Hardeland, R. \& Fuhrberg, B. 1996. Ubiquitous melatonin-Presence and effects in unicells, plants and animals. Trends Comp Biochem Physiol 2, 25-45.

Hardeland, R. 2008. Melatonin, hormone of darkness and more: occurrence, control mechanisms, actions and bioactive metabolites. Cell Mol Life Sci 65, 2001-2018. doi: 10.1007/s00018-008-8001-x.

Hardeland, R., Cardinali, D.P., Srinivasan, V., Spence, D.W., Brown, G.M. \& Pandi-Perumal, S.R. 2011. Melatonin--a pleiotropic, orchestrating regulator molecule. Prog Neurobiol 93, 350-384. doi: 10.1016/j.pneurobio.2010.12.004.

Hardeland, R., Pandi-Perumal, S.R. \& Cardinali, D.P. 2006. Melatonin. Int J Biochem Cell Biol 38, 313-316. doi: 10.1016/j.biocel.2005.08.020.

Haslam, D.W. \& James, W.P. 2005. Obesity. Lancet 366, 1197-1209. doi: 10.1016/S01406736(05)67483-1.

Hopps, E., Noto, D., Caimi, G. \& Averna, M.R. 2010. A novel component of the metabolic syndrome: the oxidative stress. Nutr Metab Cardiovasc Dis 20, 72-77. doi: 10.1016/j.numecd.2009.06.002.

Houstis, N., Rosen, E.D. \& Lander, E.S. 2006. Reactive oxygen species have a causal role in multiple forms of insulin resistance. Nature 440, 944-948. doi: 10.1038/nature04634.

Hoyos, M., Guerrero, J.M., Perez-Cano, R., Olivan, J., Fabiani, F., Garcia-Perganeda, A. \& Osuna, C. 2000. Serum cholesterol and lipid peroxidation are decreased by melatonin in dietinduced hypercholesterolemic rats. J Pineal Res 28, 150-155.

Hussain, S.A. 2007. Effect of melatonin on cholesterol absorption in rats. J Pineal Res 42, 267271. doi: 10.1111/j.1600-079X.2006.00415.x.

Hussein, M.R., Ahmed, O.G., Hassan, A.F. \& Ahmed, M.A. 2007. Intake of melatonin is associated with amelioration of physiological changes, both metabolic and morphological pathologies associated with obesity: an animal model. Int J Exp Pathol 88, 19-29. doi: 10.1111/j.1365-2613.2006.00512.x.

Kan, M.Y., Zhou, D.Z., Zhang, D., Zhang, Z., Chen, Z., Yang, Y.F., Guo, X.Z., Xu, H., He, L. \& Liu, Y. 2010. Two susceptible diabetogenic variants near/in MTNR1B are associated with fasting plasma glucose in a Han Chinese cohort. Diabet Med 27, 598-602. doi: 10.1111/j.1464-5491.2010.02975.x.

Kassayova, M., Markova, M., Bojkova, B., Adamekova, E., Kubatka, P., Ahlersova, E. \& Ahlers, I. 2006. influence of long-term melatonin administration on basic physiological and metabolic variables of young Wistar:Han rats. Biologia 61, 313-320.

Kaya, O., Kilic, M., Celik, I., Baltaci, A.K. \& Mogulkoc, R. 2010. Effect of melatonin supplementation on plasma glucose and liver glycogen levels in rats subjected to acute swimming exercise. Pak J Pharm Sci 23, 241-244.

Kelly, T., Yang, W., Chen, C.S. \& Reynolds, K., He, J. 2008. Global burden of obesity in 2005 and projections to 2030. Int J Obes (Lond) 32, 1431-1437. doi: 10.1038/ijo.2008.102. 
Kitagawa, A., Ohta, Y. \& Ohashi, K. 2011. Melatonin improves metabolic syndrome induced by high-fructose intake in rats. J Pineal Res Epub doi: 10.1111/j.1600-079X.2011.00955.x.

Kitajima, T., Kanbayashi, T., Saitoh, Y., Ogawa, Y., Sugiyama, T., Kaneko, Y., Sasaki, Y., Aizawa, R. \& Shimisu, T. 2001. The effects of oral melatonin on the autonomic function in healthy subjects. Psychiatry Clin Neurosci 55, 299-300. doi: 10.1046/j.14401819.2001.00866.x.

Korkmaz, A., Reiter, R.J., Topal, T., Manchester, L.C., Oter, S. \& Tan, D.X. 2009a. Melatonin: an established antioxidant worthy of use in clinical trials. Mol Med 15, 43-50. doi: 10.2119/molmed.2008.00117.

Korkmaz, A., Topal, T., Tan, D.X. \& Reiter, R.J. 2009b. Role of melatonin in metabolic regulation. Rev Endocr Metab Disord 10, 261-270. doi: 10.1007/s11154-009-9117-5.

Kozirog, M., Poliwczak, A.R., Duchnowicz, P., KoterMichalak, M., Sikora, J. \& Broncel, M. 2011. Melatonin treatment improves blood pressure, lipid profile, and parameters of oxidative stress in patients with metabolic syndrome. J Pineal Res 50, 261-266. doi: 10.1111/j.1600079X.2010.00835.x.

Kuzuya, T., Nakagawa, S., Satoh, J., Kanazawa, Y., Iwamoto, Y., Kobayashi, M., Nanjo, K., Sasaki, A., Seino, Y., Ito, C., Shima, K., Nonaka, K., Kadowaki, T. \& Committee of the Japan Diabetes Society on the diagnostic criteria of diabetes mellitus. 2002. Report of the Committee on the classification and diagnostic criteria of diabetes mellitus. Diabetes Res Clin Pract 55, 65-85.

Lago, R., Gomez, R., Lago, F., Gomez-Reino, J. \& Gualillo, O. 2008. Leptin beyond body weight regulation--current concepts concerning its role in immune function and inflammation. Cell Immunol 252, 139-145. doi: 10.1016/j.cellimm.2007.09.004.

Lamont, K.T., Somers, S., Lacerda, L., Opie, L.H. \& Lecour, S. 2011. Is red wine a SAFE sip away from cardioprotection? Mechanisms involved in resveratrol- and melatonin-induced cardioprotection. J Pineal Res 50, 374-380. doi: 10.1111/j.1600-079X.2010.00853.x.

Lima, F.B., Machado, U.F., Bartol, I., Seraphim, P.M., Sumida, D.H., Moraes, S.M., Hell, N.S., Okamoto, M.M., Saad, M.J., Carvalho, C.R. \& Cipolla-Neto, J. 1998. Pinealectomy causes glucose intolerance and decreases adipose cell responsiveness to insulin in rats. Am J Physiol 275, E934-41.

Lochner, A., Genade, S., Davids, A., Ytrehus, K. \& Moolman, J.A. 2006. Short- and long-term effects of melatonin on myocardial post-ischemic recovery. J Pineal Res 40, 56-63. doi: 10.1111/j.1600-079X.2005.00280.x.

Lopez, A., Garcia, J.A., Escames, G., Venegas, C., Ortiz, F., Lopez, L.C. \& Acuna-Castroviejo, D. 2009. Melatonin protects the mitochondria from oxidative damage reducing oxygen consumption, membrane potential, and superoxide anion production. $J$ Pineal Res 46, 188198. doi: 10.1111/j.1600-079X.2008.00647.x.

Markova, M., Adamekova, E., Kubatka, P. \& Bojkova, B. 2003. Effect of prolonged melatonin administration on metabolic parameters and organ weights in young male and female Sprague-Dawley rats. Acta Vet Brno 72, 163-173. 
Mazepa, R.C., Cuevas, M.J., Collado, P.S. \& Gonzalez-Gallego, J. 2000. Melatonin increases muscle and liver glycogen content in nonexercised and exercised rats. Life Sci 66, 153-160.

McLaughlin, T., Allison, G., Abbasi, F., Lamendola, C. \& Reaven, G. 2004. Prevalence of insulin resistance and associated cardiovascular disease risk factors among normal weight, overweight, and obese individuals. Metabolism 53, 495-499.

Morrison, C.D., Huypens, P., Stewart, L.K. \& Gettys, T.W. 2009. Implications of crosstalk between leptin and insulin signaling during the development of diet-induced obesity. Biochim Biophys Acta 1792, 409-416. doi: 10.1016/j.bbadis.2008.09.005.

Muhlbauer, E., Gross, E., Labucay, K., Wolgast, S. \& Peschke, E. 2009. Loss of melatonin signalling and its impact on circadian rhythms in mouse organs regulating blood glucose. Eur J Pharmacol 606, 61-71. doi: 10.1016/j.ejphar.2009.01.029.

Mukherjee, R., Banerjee, S., Joshi, N., Singh, P.K., Baxi, D. \& Ramachandran, A.V. 2011. A combination of melatonin and alpha lipoic acid has greater cardioprotective effect than either of them singly against cadmium-induced oxidative damage. Cardiovasc Toxicol 11, 78-88. doi: 10.1007/s12012-010-9092-9.

Mulder, H., Nagorny, C.L., Lyssenko, V. \& Groop, L. 2009. Melatonin receptors in pancreatic islets: good morning to a novel type 2 diabetes gene. Diabetologia 52, 1240-1249. doi: 10.1007/s00125-009-1359-y.

Myers, M.G., Cowley, M.A. \& Munzberg, H. 2008. Mechanisms of leptin action and leptin resistance. Annu Rev Physiol 70, 537-556. doi: 10.1146/annurev.physiol.70.113006.100707.

Nduhirabandi, F., Du Toit, E.F., Blackhurst, D., Marais, D. \& Lochner, A. 2011. Chronic melatonin consumption prevents obesity-related metabolic abnormalities and protects the heart against myocardial ischemia and reperfusion injury in a prediabetic model of dietinduced obesity. J Pineal Res 50, 171-182. doi: 10.1111/j.1600-079X.2010.00826.x; 10.1111/j.1600-079X.2010.00826.x.

Nieuwenhuis, R.F., Spooren, P.F. \& Tilanus, J.J. 2009. Less need for insulin, a surprising effect of phototherapy in insulin-dependent diabetes mellitus. Tijdschr Psychiatr 51, 693-697.

Nishida, S. 2005. Metabolic effects of melatonin on oxidative stress and diabetes mellitus. Endocrine 27, 131-136.

Nishida, S., Sato, R., Murai, I. \& Nakagawa, S. 2003. Effect of pinealectomy on plasma levels of insulin and leptin and on hepatic lipids in type 2 diabetic rats. J Pineal Res 35, 251-256.

Nishida, S., Segawa, T., Murai, I. \& Nakagawa, S. 2002. Long-term melatonin administration reduces hyperinsulinemia and improves the altered fatty-acid compositions in type 2 diabetic rats via the restoration of Delta-5 desaturase activity. J Pineal Res 32, 26-33.

Otani, H. 2011. Oxidative Stress as Pathogenesis of Cardiovascular Risk Associated with Metabolic Syndrome. Antioxid Redox Signal doi: 10.1089/ars.2010.3739.

Oxenkrug, G.F. \& Summergrad, P. 2010. Ramelteon attenuates age-associated hypertension and weight gain in spontaneously hypertensive rats. Ann N Y Acad Sci 1199, 114-120. doi: 10.1111/j.1749-6632.2009.05355.x. 
Oztekin, E., Mogulkoc, R., Baltaci, A.K. \& Tiftik, A.M. 2006. The influence of estradiol and progesterone and melatonin supplementation on TNF-alpha levels in ovariectomized and pinealectomized rats. Acta Biol Hung 57, 275-281. doi: 10.1556/ABiol.57.2006.3.1.

Pan, M., Song, Y.L., Xu, J.M. \& Gan, H.Z. 2006. Melatonin ameliorates nonalcoholic fatty liver induced by high-fat diet in rats. J Pineal Res 41, 79-84. doi: 10.1111/j.1600-

079X.2006.00346.x.

Pandi-Perumal, S.R., Srinivasan, V., Maestroni, G.J., Cardinali, D.P., Poeggeler, B. \& Hardeland, R. 2006. Melatonin: Nature's most versatile biological signal? FEBS J 273, 28132838. doi: 10.1111/j.1742-4658.2006.05322.x.

Pandi-Perumal, S.R., Trakht, I., Srinivasan, V., Spence, D.W., Maestroni, G.J., Zisapel, N. \& Cardinali, D.P. 2008. Physiological effects of melatonin: role of melatonin receptors and signal transduction pathways. Prog Neurobiol 85, 335-353. doi: 10.1016/j.pneurobio.2008.04.001.

Paradies, G., Petrosillo, G., Paradies, V., Reiter, R.J. \& Ruggiero, F.M. 2010. Melatonin, cardiolipin and mitochondrial bioenergetics in health and disease. $J$ Pineal Res 48, 297-310. doi: 10.1111/j.1600-079X.2010.00759.x.

Paulis, L. \& Simko, F. 2007. Blood pressure modulation and cardiovascular protection by melatonin: potential mechanisms behind. Physiol Res 56, 671-684.

Penicaud, L., Cousin, B., Leloup, C., Lorsignol, A. \& Casteilla, L.2000. The autonomic nervous system, adipose tissue plasticity, and energy balance. Nutrition 16, 903-908.

Peschke, E. 2008. Melatonin, endocrine pancreas and diabetes. J Pineal Res 44, 26-40. doi: 10.1111/j.1600-079X.2007.00519.x.

Peschke, E., Fauteck, J.D., Musshoff, U., Schmidt, F., Beckmann, A. \& Peschke, D. 2000. Evidence for a melatonin receptor within pancreatic islets of neonate rats: functional, autoradiographic, and molecular investigations. J Pineal Res 28, 156-164.

Peschke, E., Frese, T., Chankiewitz, E., Peschke, D., Preiss, U., Schneyer, U., Spessert, R. \& Muhlbauer, E. 2006. Diabetic Goto Kakizaki rats as well as type 2 diabetic patients show a decreased diurnal serum melatonin level and an increased pancreatic melatonin-receptor status. J Pineal Res 40, 135-143. doi: 10.1111/j.1600-079X.2005.00287.x.

Peschke, E., Hofmann, K., Ponicke, K., Wedekind, D. \& Muhlbauer, E. 2011. Catecholamines are the key for explaining the biological relevance of insulin-melatonin antagonisms in type 1 and type 2 diabetes. J Pineal Res Epub doi: 10.1111/j.1600-079X.2011.00951.x; 10.1111/j.1600-079X.2011.00951.x.

Peschke, E. \& Muhlbauer, E. 2010. New evidence for a role of melatonin in glucose regulation. Best Pract Res Clin Endocrinol Metab 24, 829-841. doi: 10.1016/j.beem.2010.09.001.

Peschke, E., Schucht, H. \& Muhlbauer, E. 2010. Long-term enteral administration of melatonin reduces plasma insulin and increases expression of pineal insulin receptors in both Wistar and type 2-diabetic Goto-Kakizaki rats. J Pineal Res 49, 373-381. doi: 10.1111/j.1600079X.2010.00804.x; 10.1111/j.1600-079X.2010.00804.x. 
Peschke, E., Stumpf, I., Bazwinsky, I., Litvak, L., Dralle, H. \& Muhlbauer, E. 2007. Melatonin and type 2 diabetes - a possible link? J Pineal Res 42, 350-358. doi: 10.1111/j.1600079X.2007.00426.x.

Petrosillo, G., Colantuono, G., Moro, N., Ruggiero, F.M., Tiravanti, E., Di Venosa, N., Fiore, T. \& Paradies, G. 2009. Melatonin protects against heart ischemia-reperfusion injury by inhibiting mitochondrial permeability transition pore opening. Am J Physiol Heart Circ Physiol 297, H1487-93. doi: 10.1152/ajpheart.00163.2009.

Petrosillo, G., Moro, N., Paradies, V., Ruggiero, F.M. \& Paradies, G. 2010. Increased susceptibility to $\mathrm{Ca}(2+)$-induced permeability transition and to cytochrome $\mathrm{c}$ release in rat heart mitochondria with aging: effect of melatonin. J Pineal Res 48, 340-346. doi: 10.1111/j.1600-079X.2010.00758.x.

Picinato, M.C., Haber, E.P., Carpinelli, A.R. \& Cipolla-Neto, J. 2002. Daily rhythm of glucoseinduced insulin secretion by isolated islets from intact and pinealectomized rat. $J$ Pineal Res 33, $172-177$.

Picinato, M.C., Hirata, A.E., Cipolla-Neto, J., Curi, R., Carvalho, C.R., Anhe, G.F. \& Carpinelli, A.R. 2008. Activation of insulin and IGF-1 signaling pathways by melatonin through MT1 receptor in isolated rat pancreatic islets. J Pineal Res 44, 88-94. doi: 10.1111/j.1600079X.2007.00493.x.

Poirier, P., Giles, T.D., Bray, G.A., Hong, Y., Stern, J.S., Pi-Sunyer, F.X., Eckel, R.H., American Heart Association \& Obesity Committee of the Council on Nutrition, Physical Activity, and Metabolism. 2006. Obesity and cardiovascular disease: pathophysiology, evaluation, and effect of weight loss: an update of the 1997 American Heart Association Scientific Statement on Obesity and Heart Disease from the Obesity Committee of the Council on Nutrition, Physical Activity, and Metabolism. Circulation 113, 898-918. doi: 10.1161/CIRCULATIONAHA.106.171016.

Pothiwala, P., Jain, S.K. \& Yaturu, S. 2009. Metabolic syndrome and cancer. Metab Syndr Relat Disord 7, 279-288. doi: 10.1089/met.2008.0065.

Prunet-Marcassus, B., Desbazeille, M., Bros, A., Louche, K., Delagrange, P., Renard, P., Casteilla, L. \& Penicaud, L. 2003. Melatonin reduces body weight gain in Sprague Dawley rats with diet-induced obesity. Endocrinology 144, 5347-5352. doi: 10.1210/en.2003-0693.

Puchalski, S.S., Green, J.N. \& Rasmussen, D.D. 2003. Melatonin effect on rat body weight regulation in response to high-fat diet at middle age. Endocrine 21, 163-167. doi: 10.1385/ENDO:21:2:163.

Rains, J.L. \& Jain, S.K. 2011. Oxidative stress, insulin signaling, and diabetes. Free Radical Biology and Medicine 50, 567-575. doi: DOI: 10.1016/j.freeradbiomed.2010.12.006.

Rasmussen, D.D., Boldt, B.M., Wilkinson, C.W., Yellon, S.M. \& Matsumoto, A.M. 1999. Daily melatonin administration at middle age suppresses male rat visceral fat, plasma leptin, and plasma insulin to youthful levels. Endocrinology 140, 1009-1012.

Reiter, R.J. \& Korkmaz, A. 2008. Clinical aspects of melatonin. Saudi Med J 29, 1537-1547. 
Reiter, R.J., Tan, D.X. \& Fuentes-Broto, L. 2010. Melatonin: a multitasking molecule. Prog Brain Res 181, 127-151. doi: 10.1016/S0079-6123(08)81008-4.

Reiter, R.J., Tan, D.X., Jou, M.J., Korkmaz, A., Manchester, L.C. \& Paredes, S.D. 2008. Biogenic amines in the reduction of oxidative stress: melatonin and its metabolites. Neuro Endocrinol Lett 29, 391-398.

Reiter, R.J., Tan, D.X. \& Korkmaz, A. 2009. The circadian melatonin rhythm and its modulation: possible impact on hypertension. J Hypertens Suppl 27, S17-20. doi:

10.1097/01.hjh.0000358832.41181.bf.

Reiter, R.J., Tan, D.X. \& Korkmaz, A., Ma, S. 2011. Obesity and metabolic syndrome: Association with chronodisruption, sleep deprivation, and melatonin suppression. Ann Med doi: $10.3109 / 07853890.2011 .586365$.

Reiter, R.J., Tan, D.X., Osuna, C. \& Gitto, E. 2000. Actions of melatonin in the reduction of oxidative stress. A review. J Biomed Sci 7, 444-458.

Reiter, R.J., Tan, D.X., Paredes, S.D. \& Fuentes-Broto, L. 2010a. Beneficial effects of melatonin in cardiovascular disease. Ann Med 42, 276-285. doi: 10.3109/07853890903485748.

Reiter, R.J., Manchester, L.C., FuentesBroto, L. \& Tan, D. 2010b. Cardiac hypertrophy and remodelling: pathophysiological consequences and protective effects of melatonin. $J$ Hypertens 28, S7-S12. doi: 10.1097/01.hjh.0000388488.51083.2b.

Rios-Lugo, M.J., Cano, P., Jimenez-Ortega, V., Fernandez-Mateos, M.P., Scacchi, P.A., Cardinali, D.P. \& Esquifino, A.I. 2010. Melatonin effect on plasma adiponectin, leptin, insulin, glucose, triglycerides and cholesterol in normal and high fat-fed rats. $J$ Pineal Res 49, 342348. doi: 10.1111/j.1600-079X.2010.00798.x.

Roberts, C.K. \& Sindhu, K.K. 2009. Oxidative stress and metabolic syndrome. Life Sci 84, 705712. doi: DOI: 10.1016/j.Ifs.2009.02.026.

Robeva, R., Kirilov, G., Tomova, A. \& Kumanov, P. 2006. Low testosterone levels and unimpaired melatonin secretion in young males with metabolic syndrome. Andrologia 38, 216-220. doi: 10.1111/j.1439-0272.2006.00743.x.

Robeva, R., Kirilov, G., Tomova, A. \& Kumanov, P. 2008. Melatonin-insulin interactions in patients with metabolic syndrome. J Pineal Res 44, 52-56. doi: 10.1111/j.1600079X.2007.00527.x.

Rodriguez, C., Mayo, J.C., Sainz, R.M., Antolin, I., Herrera, F., Martin, V. \& Reiter, R.J. 2004. Regulation of antioxidant enzymes: a significant role for melatonin. $J$ Pineal Res 36, 1-9.

Rojdmark, S., Berg, A., Rossner, S. \& Wetterberg, L. 1991. Nocturnal melatonin secretion in thyroid disease and in obesity. Clin Endocrinol (Oxf) 35, 61-65.

Ruger, M. \& Scheer, F.A. 2009. Effects of circadian disruption on the cardiometabolic system. Rev Endocr Metab Disord 10, 245-260. doi: 10.1007/s11154-009-9122-8. 
Sahna, E., Acet, A., Ozer, M.K., Olmez, E., 2002a. Myocardial ischemia-reperfusion in rats: reduction of infarct size by either supplemental physiological or pharmacological doses of melatonin. J Pineal Res 33, 234-238.

Sahna, E., Olmez, E. \& Acet, A. 2002b. Effects of physiological and pharmacological concentrations of melatonin on ischemia-reperfusion arrhythmias in rats: can the incidence of sudden cardiac death be reduced? J Pineal Res 32, 194-198.

Sahna, E., Parlakpinar, H., Turkoz, Y. \& Acet, A. 2005. Protective effects of melatonin on myocardial ischemia/reperfusion induced infarct size and oxidative changes. Physiol Res 54, 491-495.

Sallinen, P., Manttari, S., Leskinen, H., Ilves, M., Vakkuri, O., Ruskoaho, H. \& Saarela, S. 2007. The effect of myocardial infarction on the synthesis, concentration and receptor expression of endogenous melatonin. J Pineal Res 42, 254-260. doi: 10.1111/j.1600-079X.2006.00413.x.

Samimi-Fard, S., Abreu-Gonzalez, P., Dominguez-Rodriguez, A. \& Jimenez-Sosa, A. 2011. A case-control study of melatonin receptor type $1 \mathrm{~A}$ polymorphism and acute myocardial infarction in a Spanish population. J Pineal Res Epub. doi: 10.1111/j.1600079X.2011.00903.x.

Sanchez-Barcelo, E.J., Mediavilla, M.D., Tan, D.X. \& Reiter, R.J. 2010. Clinical uses of melatonin: evaluation of human trials. Curr Med Chem 17, 2070-2095.

Sanchez-Hidalgo, M., Lu, Z., Tan, D.X., Maldonado, M.D., Reiter, R.J. \& Gregerman, R.I. 2007. Melatonin inhibits fatty acid-induced triglyceride accumulation in ROS17/2.8 cells: implications for osteoblast differentiation and osteoporosis. Am J Physiol Regul Integr Comp Physiol 292, R2208-15. doi: 10.1152/ajpregu.00013.2007.

Sanchez-Mateos, S., Alonso-Gonzalez, C., Gonzalez, A., Martinez-Campa, C.M., Mediavilla, M.D., Cos, S. \& Sanchez-Barcelo, E.J. 2007. Melatonin and estradiol effects on food intake, body weight, and leptin in ovariectomized rats. Maturitas 58, 91-101. doi: 10.1016/j.maturitas.2007.06.006.

Sartori, C., Dessen, P., Mathieu, C., Monney, A., Bloch, J., Nicod, P., Scherrer, U. \& Duplain, H. 2009. Melatonin improves glucose homeostasis and endothelial vascular function in highfat diet-fed insulin-resistant mice. Endocrinology 150, 5311-5317. doi: 10.1210/en.20090425.

Scarpace, P.J. \& Zhang, Y. 2009. Leptin resistance: a prediposing factor for diet-induced obesity. Am J Physiol Regul Integr Comp Physiol 296, R493-500. doi: 10.1152/ajpregu.90669.2008.

Shafii, M., MacMillan, D.R., Key, M.P., Kaufman, N. \& Nahinsky, I.D. 1997. Case study: melatonin in severe obesity. J Am Acad Child Adolesc Psychiatry 36, 412-416. doi: 10.1097/00004583-199703000-00021.

She, M., Deng, X., Guo, Z., Laudon, M., Hu, Z., Liao, D., Hu, X., Luo, Y., Shen, Q., Su, Z. \& Yin, W. 2009. NEU-P11, a novel melatonin agonist, inhibits weight gain and improves insulin sensitivity in high-fat/high-sucrose-fed rats. Pharmacol Res 59, 248-253. doi: 10.1016/j.phrs.2009.01.005. 
Shieh, J.M., Wu, H.T., Cheng, K.C. \& Cheng, J.T. 2009. Melatonin ameliorates high fat dietinduced diabetes and stimulates glycogen synthesis via a PKCzeta-Akt-GSK3beta pathway in hepatic cells. J Pineal Res 47, 339-344. doi: 10.1111/j.1600-079X.2009.00720.x.

Song, C.K. \& Bartness, T.J. 2001. CNS sympathetic outflow neurons to white fat that express MEL receptors may mediate seasonal adiposity. Am J Physiol Regul Integr Comp Physiol 281, R666-72.

Song, Y.M. \& Chen, M.D. 2009. Effects of melatonin administration on plasma leptin concentration and adipose tissue leptin secretion in mice. Acta Biol Hung 60, 399-407. doi: 10.1556/ABiol.60.2009.4.6.

Srinivasan, V., Spence, D.W., Pandi-Perumal, S.R., Trakht, I. \& Cardinali, D.P. 2008. Therapeutic actions of melatonin in cancer: possible mechanisms. Integr Cancer Ther 7, 189203. doi: $10.1177 / 1534735408322846$.

Srivastava, R.K. \& Krishna, A. 2010. Melatonin modulates glucose homeostasis during winter dormancy in a vespertilionid bat, Scotophilus heathi. Comp Biochem Physiol A Mol Integr Physiol 155, 392-400. doi: 10.1016/j.cbpa.2009.12.006.

Tam, C.H., Ho, J.S., Wang, Y., Lee, H.M., Lam, V.K., Germer, S., Martin, M., So, W.Y., Ma, R.C., Chan, J.C. \& Ng, M.C. 2010. Common polymorphisms in MTNR1B, G6PC2 and GCK are associated with increased fasting plasma glucose and impaired beta-cell function in Chinese subjects. PLoS One 5, e11428. doi: 10.1371/journal.pone.0011428.

Tan, D.X., Manchester, L.C., FuentesBroto, L., Paredes, S.D. \& Reiter, R.J. 2011. Significance and application of melatonin in the regulation of brown adipose tissue metabolism: relation to human obesity. Obesity Reviews 12, 167-188. doi: 10.1111/j.1467-789X.2010.00756.x.

Tan, D.X., Manchester, L.C., Terron, M.P., Flores, L.J. \& Reiter, R.J. 2007. One molecule, many derivatives: a never-ending interaction of melatonin with reactive oxygen and nitrogen species? J Pineal Res 42, 28-42. doi: 10.1111/j.1600-079X.2006.00407.x.

Tengattini, S., Reiter, R.J., Tan, D.X., Terron, M.P., Rodella, L.F. \& Rezzani, R. 2008. Cardiovascular diseases: protective effects of melatonin. J Pineal Res 44, 16-25. doi: 10.1111/j.1600-079X.2007.00518.x.

Tesauro, M. \& Cardillo, C. 2011. Obesity, blood vessels and metabolic syndrome. Acta Physiologica 203, 279-286. doi: 10.1111/j.1748-1716.2011.02290.x.

Thakor, A.S., Herrera, E.A., SeronFerre, M. \& Giussani, D.A. 2010. Melatonin and vitamin C increase umbilical blood flow via nitric oxide-dependent mechanisms. $J$ Pineal Res 49, 399406. doi: 10.1111/j.1600-079X.2010.00813.x.

Tunstall, R.R., Shukla, P., Grazul-Bilska, A., Sun, C. \& O'Rourke, S.T. 2011. MT2 receptors mediate the inhibitory effects of melatonin on nitric oxide-induced relaxation of porcine isolated coronary arteries. J Pharmacol Exp Ther 336, 127-133. doi: 10.1124/jpet.110.174482.

Vincent, H.K., Innes, K.E. \& Vincent, K.R. 2007. Oxidative stress and potential interventions to reduce oxidative stress in overweight and obesity. Diabetes Obes Metab 9, 813-839. doi: 10.1111/j.1463-1326.2007.00692.x. 
Vural, H., Sabuncu, T., Arslan, S.O. \& Aksoy, N. 2001. Melatonin inhibits lipid peroxidation and stimulates the antioxidant status of diabetic rats. J Pineal Res 31, 193-198.

Wiesenberg, I., Missbach, M. \& Carlberg, C. 1998. The potential role of the transcription factor RZR/ROR as a mediator of nuclear melatonin signaling. Restor Neurol Neurosci 12, 143-150.

Wolden-Hanson, T., Mitton, D.R., McCants, R.L., Yellon, S.M., Wilkinson, C.W., Matsumoto, A.M. \& Rasmussen, D.D. 2000. Daily melatonin administration to middle-aged male rats suppresses body weight, intraabdominal adiposity, and plasma leptin and insulin independent of food intake and total body fat. Endocrinology 141, 487-497.

Yildiz, M., Akdemir, O., 2009. Assessment of the effects of physiological release of melatonin on arterial distensibility and blood pressure. Cardiol Young 19, 198-203. doi: $10.1017 /$ S1047951109003692.

Zanquetta, M.M., Seraphim, P.M., Sumida, D.H., Cipolla-Neto, J. \& Machado, U.F. 2003. Calorie restriction reduces pinealectomy-induced insulin resistance by improving GLUT4 gene expression and its translocation to the plasma membrane. J Pineal Res 35, 141-148.

Zawilska, J.B., Skene, D.J. \& Arendt, J. 2009. Physiology and pharmacology of melatonin in relation to biological rhythms. Pharmacol Rep 61, 383-410.

Zieba, D.A., Kirsz, K., Molik, E., Romanowicz, K. \& Wojtowicz, A.K. 2011. Effects of orexigenic peptides and leptin on melatonin secretion during different photoperiods in seasonal breeding ewes: An in vitro study. Domest Anim Endocrinol 40, 139-146. doi: 10.1016/j.domaniend.2010.09.008. 
TABLE 1 POTENTIAL MELATONIN'S EFFECTS IN OBESITY- RELATED METABOLIC ALTERATIONS

\begin{tabular}{|c|c|c|c|c|}
\hline \multicolumn{2}{|c|}{ Parameters } & Before treatment & $\begin{array}{l}\text { Treatment } \\
\text { Effects }\end{array}$ & References \\
\hline \multicolumn{2}{|c|}{ Body weight } & $\uparrow$ & $\downarrow$ & $\begin{array}{l}\text { (Rasmussen et al. 1999,Wolden-Hanson et al. 2000,Prunet-Marcassus et al. 2003,Puchalski et al. } \\
\text { 2003, Hussein et al.2007) }\end{array}$ \\
\hline \multicolumn{2}{|c|}{ Visceral fat } & $\uparrow$ & $\downarrow$ & (Rasmussen et al.1999,Prunet-Marcassus et al. 2003,Puchalski et al. 2003, She et al. 2009) \\
\hline \multirow{9}{*}{ Blood } & Fasting glucose & $\uparrow$ & $\downarrow$ & (Prunet-Marcassus et al. 2003, Shieh et al. 2009, Peschke et al. 2010,Rios-Lugo et al. 2010) \\
\hline & Insulin & $\uparrow$ & $\downarrow$ & (Nishida et al. 2002,Puchalski et al. 2003, Sartori et al. 2009,Shieh et al. 2009,Peschke et al. 2010) \\
\hline & HDL-C & $\downarrow$ & $\uparrow$ & (Hussain 2007,Hussein et al. 2007, She et al. 2009, Agil et al. 2011a) \\
\hline & LDL-C & $\uparrow$ & $\downarrow$ & (Hussein et al. 2007, Agil et al. 2011a, Kozirog et al. 2011) \\
\hline & TG & $\uparrow$ & $\downarrow$ & (Nishida et al.2002,Hussain 2007,Rios-Lugo et al.2010,Agil et al.2011a,Kozirog et al.2011) \\
\hline & VLDL & $\uparrow$ & $\downarrow$ & (Hoyos et al.2000) \\
\hline & Leptin & $\uparrow$ & $\downarrow$ or $\uparrow$ & $\begin{array}{l}\downarrow \text { (Wolden-Hanson et al.2000, Nishida et al.2002,Prunet-Marcassus et al.2003,Puchalski et al.2003) } \\
\text { or } \uparrow \text { (Baltaci \& Mogulkoc2007, Song \& Chen2009) }\end{array}$ \\
\hline & Adiponectin & $\downarrow$ or $\uparrow(?)$ & $\uparrow$ or $\downarrow(?)$ & $\uparrow$ (Agil et al. 2011b, Kitagawa et al. 2011) or $\downarrow$ (Rios-Lugo et al.2010) (?) \\
\hline & TNF- $\alpha$ & $\uparrow$ & $\downarrow$ & (Nishida 2005,Oztekin et al.2006, Kitagawa et al. 2011) \\
\hline \multirow{6}{*}{ Liver } & Fibrinogen secretion & $\uparrow$ & $\downarrow$ & (Bekyarova et al.2010) \\
\hline & TG \& VLDL release & $\uparrow$ & $\downarrow$ & (Hussain 2007) \\
\hline & Glucose release & $\uparrow$ & $\downarrow$ & (Kaya et al.2010) \\
\hline & C-reactive protein & $\uparrow$ & $\downarrow$ & (Bekyarova et al.2010) \\
\hline & Glycogen content & $\downarrow$ & $\uparrow$ & (Shieh et al.2009) \\
\hline & Liver weight & $\uparrow$ & $\downarrow$ & (Pan et al.2006) \\
\hline \multirow{3}{*}{ Muscle } & Insulin sensitivity (glucose uptake) & $\downarrow$ & $\uparrow$ & (Sartori et al.2009,Srivastava \& Krishna2010) \\
\hline & FFA /TG uptake & $\uparrow$ & $\downarrow$ & (Dauchy et al.2003) \\
\hline & Glycogen content & $\downarrow$ & $\uparrow$ & (Mazepa et al.2000) \\
\hline \multirow{4}{*}{$\begin{array}{l}\text { Heart \& } \\
\text { Vessels }\end{array}$} & Blood pressure & $\uparrow$ & $\downarrow$ & (Paulis \& Simko2007, Kozirog et al.2011) \\
\hline & Heart rate & $\uparrow$ & $\downarrow$ & (Hussein et al. 2007) \\
\hline & Endothelial dysfunction & $\uparrow$ & $\downarrow$ & (Sartori et al. 2009) \\
\hline & Cardiomyopathy /Hypertrophy & $\uparrow$ & $\downarrow$ & (Bertuglia \& Reiter2007, Ghosh et al. 2007) \\
\hline
\end{tabular}


Table 1 Only some references have been indicated in this table as evidence of the potential effects of melatonin in metabolic

syndrome. $\downarrow$ : decreases or attenuates; $\uparrow$ : increases or elevates; (?): needs more studies/unusual model of obesity; FFA: free fatty acids; TNF-a: tumor necrosis factor-alpha; VLDL: very low density lipoprotein; HDL-C: high density lipoprotein-cholesterol; LDL-C: Low density lipoprotein-cholesterol; TG: triglyceride. 


\section{LEGEND FOR FIGURES}

Figure 1 Melatonin improves obesity-induced metabolic alterations by reducing circulating free fatty acids (FFA) and hyperglycaemia and dyslipidaemia as well as hyperinsulinaemia with a concomitant increased in high density lipoprotein-cholesterol (HDL-C) and adiponectin. In addition, melatonin improves leptin and insulin resistance and hypertension. These effects are still complex and interconnected and may lead to improvement of coronary heart disease (CHD), heart failure and arrhythmias. As evidence, we showed that melatonin administration reduced myocardial ischaemia reperfusion $(\mathrm{I} / \mathrm{R})$ damage by reducing infarct size, improving post-ischaemic myocardial function recovery via activation of reperfusion injury salvage protein kinases (PKB/Atk and ERK1/2). $\downarrow$ : reduction, $\uparrow:$ increase,?: no information available, FFA: free fatty acids; LDL-C: Low density lipoprotein-cholesterol; TG: triglyceride, GLUT: glucose transport, SOD: superoxide dismutase, BW: body weight, Visc fat: visceral fat, HW: heart weight, TBARS: thiobarbituric acid reactive substrates, GSH-Px: glutathione peroxidase (References see in the text).

Figure 2 Melatonin administration was associated with a significant increase in glycogen synthesis in hepatic cells and improved glucose homeostasis in skeletal muscle by activation of eNOs (endothelial nitric oxide synthase). How melatonin stimulated phosphorylation of IRS remains unknown. The effect of melatonin in glucose uptake remains unclear. The mitogenactivated protein kinase (MAPK) pathway was not included in the figure. ?: no available data, IR: insulin receptor, IRS-1: insulin receptor substate 1, PI-3K: phosphatidylinositol-3-kinase,

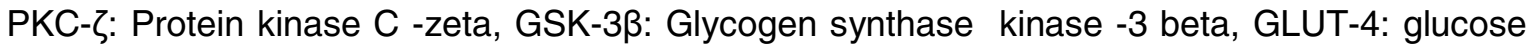
transporter -4, Mel: melatonin, MT1/2: melatonin receptor 1, 2, Ins: Insulin. (References see in the text). 


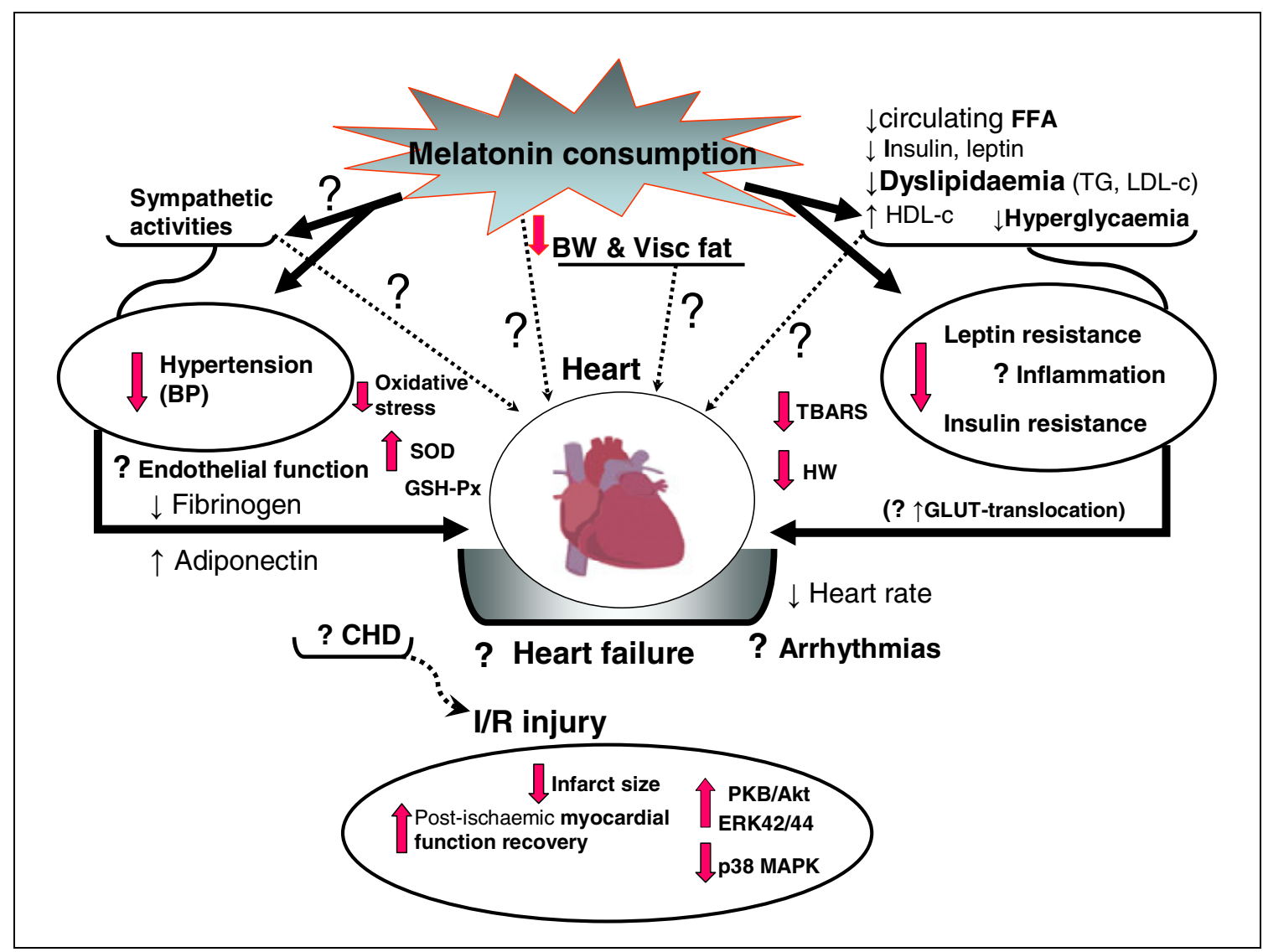

Figure 1 Hypothetical representation of the beneficial actions of melatonin in obesity and its related cardiovascular complications. 


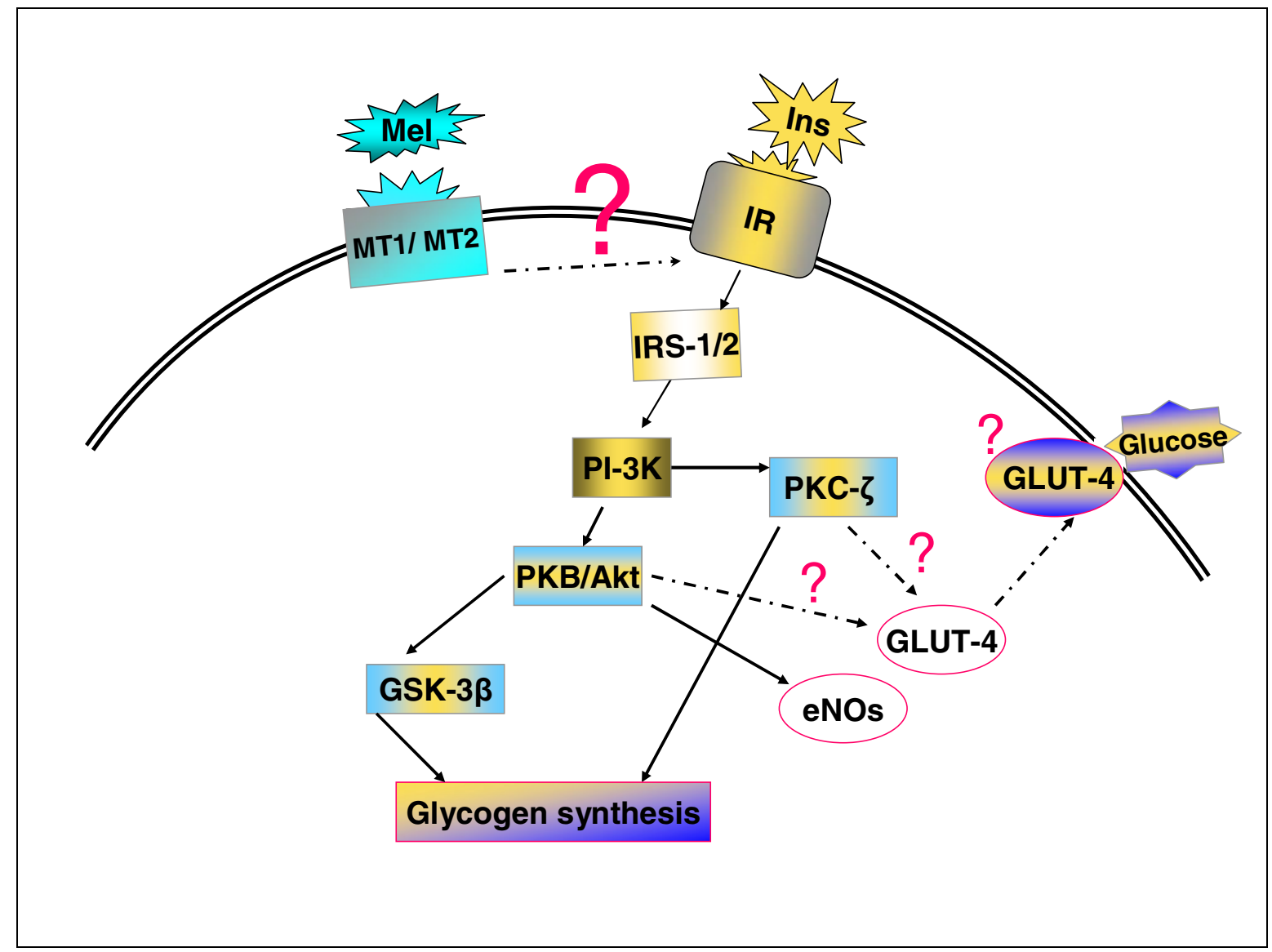

Figure 2 Simplified representation of the effect of melatonin on insulin signaling pathway in peripheral tissues 